\title{
ANALISIS PERILAKU TANAH DISPERSIF TERHADAP DINDING PENAHAN TANAH DALAM PEKERJAAN DEWATERING KONSTRUKSI BASEMENT
}

\author{
Arya Febrian ${ }^{1}$ dan Chaidir Anwar Makarim² \\ ${ }^{\text {I}}$ Program Studi Sarjana Teknik Sipil, Universitas Tarumanagara, Jl. Letjen S. Parman No.1 Jakarta \\ Email: aryafebrian97@gmail.com \\ ${ }^{2}$ Program Studi Sarjana Teknik Sipil, Universitas Tarumanagara, Jl. Letjen S. Parman No.1 Jakarta \\ Email: chaidir259@gmail.com
}

\begin{abstract}
ABSTRAK
Skripsi ini menganalisis tentang metode pelaksanaan dalam pembuatan basement 3 lantai menggunakan sistem dewatering dengan dinding penahan tanah pada tanah dispersif. Tanah dispersif adalah tanah yang mudah tererosi dan terurai apabila berinteraksi dengan air, sehingga dapat menyebabkan banyak kerusakan. Perilaku tanah dispersif terhadap dinding penahan tanah juga sangat berpengaruh pada pekerjaan konstruksi dan dapat mempengaruhi kriteria desain suatu struktur. Tujuan dari analisis ini adalah untuk memberi peringatan pentingnya memahami perilaku tanah di lokasi konstruksi, terutama untuk tanah sensitif yang sangat memerlukan keberhati-hatian desain dan juga desain yang bersifat koservatifKemudian, analisis dilanjutkan dengan pengecekan kestabilan dinding penahan tanah dengan menggunakan bantuan program. Dalam simulasi program, syarat angka keamanan dan batas deformasi dinding penahan tanah ditingkatkan untuk mencegah kemungkinan terburuk terjadi karena kondisi lapangan dan simulasi pada program tidak sepenuhnya sama. Analisis pada program menunjukkan bahwa kondisi drained ( $\mathrm{SF}=2.3394)$ memiliki angka keamanan lebih kecil dari kondisi undrained ( $\mathrm{SF}=3.5499)$. Hal ini membenarkan teori bahwa pada kondisi drained, tanah memiliki permeabilitas tinggi sehingga air dapat dengan mudah mengalir keluar masuk pada tanah.
\end{abstract}

Kata kunci: basement, dewatering, tanah dispersif, dinding penahan tanah.

\section{PENDAHULUAN}

\section{Latar belakang}

Seiring berjalannya waktu, keterbatasan lahan mendorong dilakukannya prinsip pembangunan basement sebagai salah satu bentuk efisiensi lahan. Dalam pekerjaan basement proses galian tidak dapat dihindari. Pekerjaan galian harus mendapat perhatian khusus, seperti galian basement yang terletak di bawah muka air tanah yang dapat mempengaruhi lingkungan sekitar galian. Sehingga, perlu menjaga galian tetap dalam keadaan kering melalui proses pengeringan tanah dengan sistem dewatering.

Dalam melakukan pekerjaan dewatering terutama pada tanah dispersif, diperlukan peninjauan kondisi tanah pada lokasi galian untuk menghindari dampak negatif yang dapat timbul seperti terganggunya stabilitas muka air tanah. Tanah dispersif merupakan tanah yang belum dikenal luas oleh orang-orang sehingga sulit untuk ditangani dan perlu penanganan khusus oleh ahlinya. Hal tersebut terjadi, pada salah satu pembangunan apartemen di area Jakarta Pusat yang berdampak pada bangunan sekitar lokasi galian, salah satunya bangunan rumah sakit yang terletak tidak jauh dari lokasi. Oleh karena itu, diperlukan dinding penahan tanah dalam pekerjaan dewatering konstruksi basement agar tidak terjadi aliran air di sekeliling luar area galian.

Maksud dan tujuan dari penulisan skripsi ini untuk menganalisis dan menggambarkan perilaku tanah dispersif terhadap dinding penahan tanah serta dampak negatif yang dapat timbul akibat kurangnya pemahaman dan perencanaan terhadap tanah dispersif. Analisis lebih lanjut dilakukan dengan menggunakan program.

\section{Tujuan penelitian}

Tujuan dari penelitian ini adalah menjelaskan karakteristik air pada tanah saat dilakukan konstruksi galian di bawah muka air tanah, menjelaskan apa itu dewatering, menjelaskan perilaku tanah dispersif terhadap dinding penahan tanah dan menjelaskan hasil perhitungan dengan bantuan program terhadap pekerjaan galian yang menggunakan dinding penahan tanah. 


\section{TINJAUAN PUSTAKA}

\section{Basement}

Dalam pengertian umum, basement adalah ruangan di bawah permukaan tanah yang terletak pada sebuah gedung atau rumah. Basement dibangun sebagai bentuk usaha untuk mengoptimalkan penggunaan lahan yang semakin terbatas dan mahal, biasanya digunakan sebagai lahan parkir atau ruang utilitas. Metode konstruksi basement dibedakan menjadi 2, yaitu bottom-up construction dan top-down consruction. Pada metode bottom-up construction, galian dilakukan hingga elevasi rencana terlebih dahulu baru dilakukan pekerjaan struktur konstruksi basement. Sedangkan pada top-down consruction, pekerjaan struktur basement dilaksanakan bersamaan dengan pekerjaan galian (Asiyanto, 2008).

\section{Dewatering}

Dewatering adalah suatu proses pengendalian air tanah yang dilakukan untuk mengeringkan atau mengurangi air galian pondasi agar tidak mengganggu dan menghambat proses pelaksanaan suatu pekerjaan konstruksi, terutama untuk pelaksanaan bagian struktur yang berada di bawah muka air tanah. Terdapat tiga metode dasar dalam mengendalikan air tanah. Ketiga metode tersebut adalah:

1. Open pumping, air tanah dibiarkan mengalir ke dalam lubang galian, kemudian dipompa keluar melalui sumur/selokan penampung di dasar galian.

2. Predrainage, muka air tanah (water table) diturunkan terlebih dahulu sebelum proses penggalian dimulai dengan menggunakan wells, wellpoints, dan sistem lainnya.

3. Cut off, aliran air tanah dipotong dengan menggunakan sheet pile, diaphragm wall, secant piles, slurry trenches, dan beberapa cara lainnya.

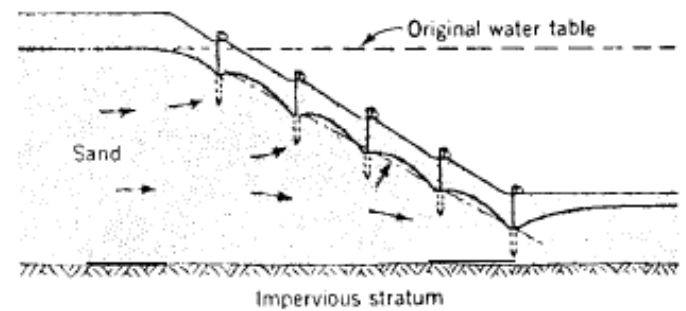

Gambar 1. Sistem wellpoint (Joint Department of the Army, the Air Force, and the Navy, 1985)

Pekerjaan dewatering tidak sepenuhnya berjalan mulus tanpa akibat-akibat samping terhadap kondisi lingkungan sekitarnya. Dewatering kadang dapat mengakibatkan settlement pada tanah sekitar, bahkan terkadang disertai dengan kerusakan struktur bangunan yang ada. Hal ini diakibatkan karena tersedotnya partikel halus dari dalam tanah oleh kegiatan penyedotan air tanah yang menyebabkan terjadinya piping pada tanah.

Jadi sebelum dilaksanakannya pekerjaan dewatering maka terlebih dahulu dibuat perencanaan yang matang disertai dengan studi terhadap AMDAL (Analisa Mengenai Dampak Lingkungan Hidup) dan hal-hal lain yang dapat mengakibatkan dampak negatif yang tidak diinginkan.

\section{Dinding penahan tanah}

Dinding penahan tanah merupakan salah satu hal yang penting, terutama dalam pembangunan konstruksi basement yang dilakukan pada tanah sensitif. Hal ini dikarenakan, dinding penahan tanah berguna untuk menjaga kondisi tanah sekitar terus stabil dan mengurangi kemungkinan terjadinya longsor atau ambles. Selain dinding penahan tanah, kondisi tanah di sekitar lokasi juga sangat berpengaruh besar dalam pekerjaan konstruksi basement. Sehingga, perlu adanya peninjauan yang tepat apakah kondisi tanah yang tersedia memungkinkan untuk dilakukan konstruksi basement.

Kondisi tanah juga dapat mempengaruhi desain dalam perencanaan konstruksi, terutama bagi tanah yang sensitif seperti tanah dispersif, tanah lunak, tanah berpasir dan lainnya. Tanah seperti yang disebutkan dapat bergerak jika berinteraksi dengan air, sehingga sangat rentan terhadap erosi. Oleh karena itu, tanah yang sensitif perlu ditinjau lebih lanjut dan ditangani secara khusus. Peran dinding penahan tanah juga sangat penting, karena jika dinding 
penahan tanah tidak kuat atau terjadi kebocoran, meskipun kecil tetap akan sangat berdampak pada lingkungan disekitarnya.

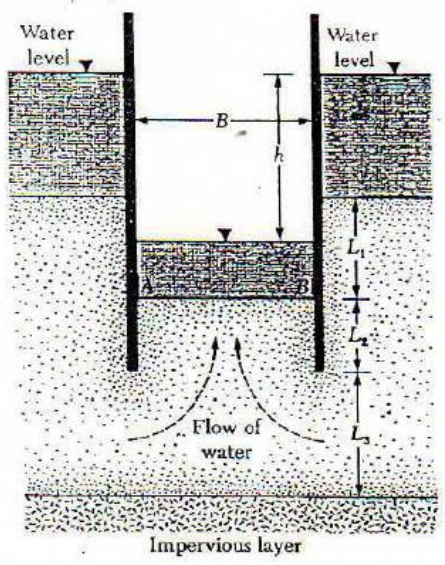

Gambar 2. Ilustrasi Dinding Penahan Tanah pada Tanah Pasir (Braja M. Das, 1998)

\section{Angkur (tie back anchor)}

Dinding penahan tanah membutuhkan sistem penunjang yaitu angkur jika terjadi deformasi yang cukup besar pada dinding. Angkur, seperti yang ditunjukkan pada Gambar 3., bertujuan untuk mengurangi bending moment, menambah kekuatan lereng, dan meminimalkan deformasi yang terjadi. Prinsip kerja angkur adalah mentransfer gaya tarik akibat pergerakan tanah dengan mengandalkan gaya gesek antara angkur dengan tanah di sekitarnya.

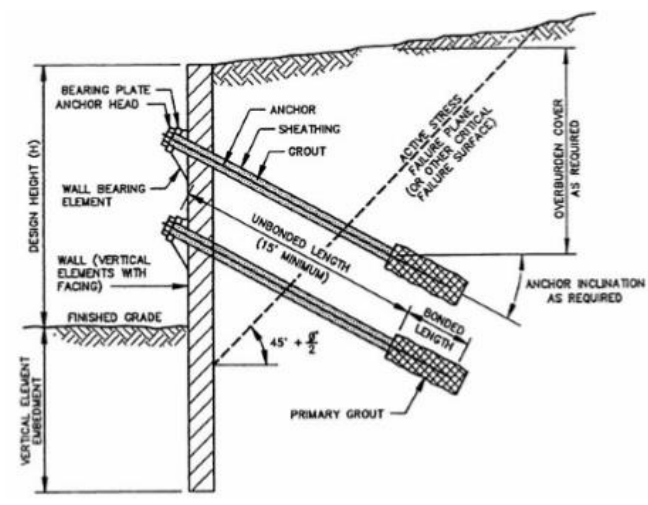

Gambar 3. Angkur (Robert W. Day, 2005)

\section{Tanah dispersif}

Tanah dispersif (dispersive soils) merupakan tanah yang kurang stabil, yang sangat mudah tererosi dan berubah menjadi partikel-partikel kecil jika berinteraksi dengan air. Hal ini terjadi karena air pori tanah dispersif mengandung larutan sodium dalam kadar yang tinggi, sehingga mineral lempung di dalamnya akan diselimuti oleh lapisan air dua kali lebih tebal dibandingkan dengan lempung pada umumnya. Kondisi ini menyebabkan terjadinya tegangan tolak antar partikel lempung sehingga apabila terendam air maka pertikel lempung tersebut akan lepas dan larut didalam air.

Secara visual, tanah dispersif dapat dikenali dengan adanya pola retakan dan lubang hingga membentuk kubangan air pada tanah. Untuk memastikan tanah berdispersif, dapat dilakukan berbagai macam tes, seperti crumb test, SCS double hydrometer test, pinhole test dan chemical test. 


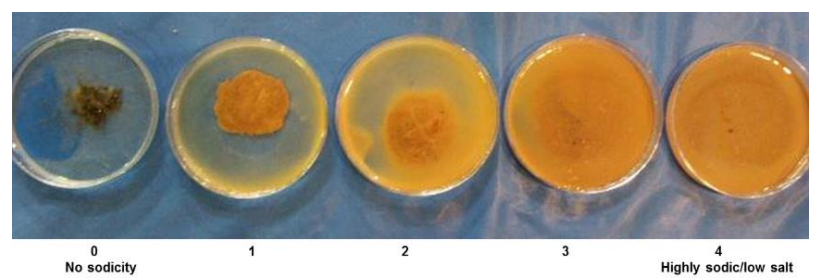

Gambar 4. Hasil crumb test (http://www.ccmaknowledgebase.vic.gov.au/brown_book/04_Sodic.htm)

\section{METODOLOGI PENELITIAN}

Penelitian ini dilakukan berdasarkan hasil analisis dengan bantuan program. Dalam melaksanakan penelitian dan analisis, langkah-langkah yang ditempuh penulis digambarkan melalui diagram alir penelitian seperti pada Gambar 5 .

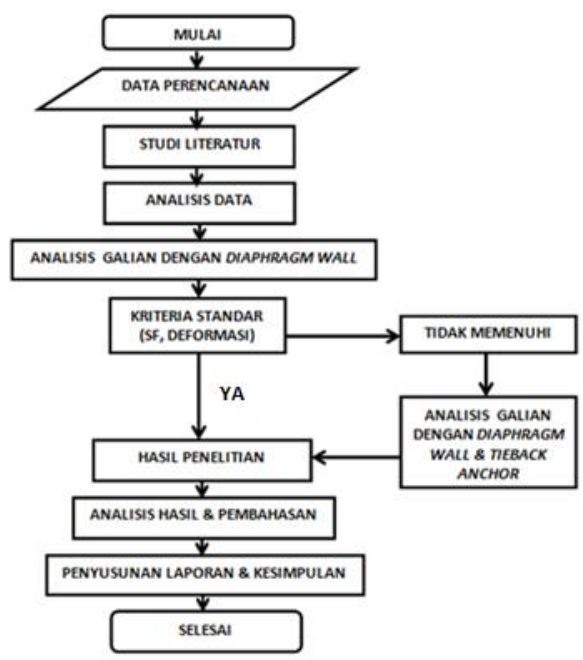

Gambar 5. Diagram Alir Penelitian

\section{ANALISIS DAN PEMBAHASAN}

\section{Parameter tanah}

Jenis tanah yang akan digunakan dalam simulasi galian ini sesuai dengan data tanah yang akan ditinjau. Berdasarkan data tanah yang akan ditinjau, dibedakan dua kondisi yaitu kondisi drained (jangka panjang) dan undrained (jangka pendek). Hal tersebut dilakukan untuk mengetahui kondisi saat penggalian selesai dilaksanakan (end of construction) yang dianalisis dengan menggunakan kondisi undrained dan pada masa yang akan datang yang dianalisis mengunakan kondisi drained. Kedua parameter dapat dilihat pada Tabel 1. dan Tabel 2.

Tabel 1. Parameter Tanah Kondisi Drained

\begin{tabular}{cccccccc}
\hline Parameter & & clay & fine sand & silty clay & fine sand & silty clay & Satuan \\
\hline Kedalaman & $h$ & $0-5$ & $5-9$ & $9-14$ & $14-19$ & $19-20$ & $\mathrm{~m}$ \\
\hline Model material & Model & $\mathrm{MC}$ & $\mathrm{MC}$ & $\mathrm{MC}$ & $\mathrm{MC}$ & $\mathrm{MC}$ & - \\
\hline Jenis perilaku & Jenis & drained & drained & drained & drained & drained & - \\
\hline N-SPT & $N$ & 2 & 6 & 10 & 18 & 9 & - \\
\hline Berat isi tanah di atas M.A.T & $\gamma_{\text {unsat }}$ & 16 & 14,4 & 16,9 & 15,5 & 16,7 & $\mathrm{kN} / \mathrm{m}^{3}$ \\
\hline Brt. isi tanah di bawah M.A.T & $\gamma_{\text {sat }}$ & 16 & 18 & 18,6 & 19,5 & 18,3 & $\mathrm{kN} / \mathrm{m}^{3}$ \\
\hline Permeabilitas & $k$ & $1.10^{-5}$ & 1 & $1.10^{-5}$ & 1 & $1.10^{-5}$ & $\mathrm{~m} / \mathrm{hari}^{-5}$ \\
\hline
\end{tabular}




\begin{tabular}{cccccccc}
\hline Modulus Young & $E_{r e f}$ & 5040 & 13000 & 30000 & 30500 & 27000 & $\mathrm{kN} / \mathrm{m}^{2}$ \\
\hline Angka Poisson & $v$ & 0,35 & 0,3 & 0,35 & $0,+3$ & 0,35 & - \\
\hline Kohesi & $c_{r e f}$ & 2,8 & 1 & 13,4 & 1 & 12 & $\mathrm{kN} / \mathrm{m}^{2}$ \\
\hline Sudut geser & $\phi$ & 20 & 31 & 23 & 37 & 23 & 0 \\
\hline Sudut dilatansi & $\psi$ & 0 & 1 & 0 & 7 & 0 & 0 \\
\hline Faktor reduksi antarmuka & $R_{\text {inter }}$ & 0,9 & 0,8 & 0,85 & 1 & 1 \\
\hline
\end{tabular}

Tabel 2. Parameter Tanah Kondisi Undrained

\begin{tabular}{cccccccc}
\hline Parameter & & clay & fine sand & silty clay & fine sand & silty clay & Satuan \\
\hline Kedalaman & $h$ & $0-5$ & $5-9$ & $9-14$ & $14-19$ & $19-20$ & $\mathrm{~m}$ \\
\hline Model material & Model & $\mathrm{MC}$ & $\mathrm{MC}$ & $\mathrm{MC}$ & $\mathrm{MC}$ & $\mathrm{MC}$ & - \\
\hline Jenis perilaku & Jenis & undrained & drained & undrained & drained & undrained & - \\
\hline N-SPT & $N$ & 2 & 6 & 10 & 18 & 9 & - \\
\hline Berat isi tanah di atas M.A.T & $\gamma_{\text {unsat }}$ & 16 & 14,4 & 16,9 & 15,5 & 16,7 & $\mathrm{kN} / \mathrm{m}^{3}$ \\
\hline Brt. isi tanah di bawah M.A.T & $\gamma_{\text {sat }}$ & 16 & 18 & 18,6 & 19,5 & 18,3 & $\mathrm{kN} / \mathrm{m}^{3}$ \\
\hline Permeabilitas & $k$ & 1.10 & 1 & 1.10 & 1 & $1.10^{-5}$ & $\mathrm{~m} / \mathrm{hari}^{-5}$ \\
\hline Modulus Young & $E_{\text {ref }}$ & 5040 & 13000 & 30000 & 30500 & 27000 & $\mathrm{kN} / \mathrm{m}^{2}$ \\
\hline Angka Poisson & $v$ & 0,35 & 0,3 & 0,35 & 0,3 & 0,35 & - \\
\hline Kohesi & $c_{\text {ref }}$ & 14 & 1 & 67 & 1 & 60 & $\mathrm{kN} / \mathrm{m}^{2}$ \\
\hline Sudut geser & $\phi$ & 0 & 31 & 0 & 37 & 0 & ${ }^{2}$ \\
\hline Sudut dilatansi & $\psi$ & 0 & 1 & 0 & 7 & 0 & 1 \\
\hline Faktor reduksi antarmuka & $R_{\text {inter }}$ & 0,9 & 0,8 & 0,85 & 1 & -
\end{tabular}

\section{Parameter dinding diafragma}

Dinding penahan tanah menggunakan tipe diaphragm wall atau dinding diafragma yang mempunyai tebal 1,2 meter. Dinding penaha tanah dimodelkan sebagai elemen pelat pada program. Parameter dan ukuran dapat dilihat pada Tabel 3.

Tabel 3. Parameter Dinding Diafragma

\begin{tabular}{lccc}
\hline \multicolumn{1}{c}{ Parameter } & Nama & Nilai & Satuan \\
\hline Jenis Perilaku & Jenis material & Elastis & - \\
\hline Kekakuan normal & $E A$ & $1,872.10^{8}$ & $\mathrm{kN} / \mathrm{m}$ \\
\hline Kekauan lentur & $E I$ & $2,2464.10^{7}$ & $\mathrm{kNm} / \mathrm{m}$ \\
\hline Ketebalan ekivalen & $d$ & 1,2 & $\mathrm{~m}$ \\
\hline Berat & $w$ & 9,6 & $\mathrm{kN} / \mathrm{m} / \mathrm{m}$ \\
\hline Angka Poisson & $v$ & 0,15 & - \\
\hline
\end{tabular}

\section{Parameter tie back anchor}


Penentuan parameter ini bersifat fleksibel dan menyesuaikan dengan kondisi lapangan. Prinsip utama dari pemasangan tie back anchor adalah mengurangi deformasi dinding dengan menempatkan bonded (grout body) pada lapisan tanah keras. Parameter angkur yang digunakan dapat dilihat pada Tabel 4. dan Tabel 5.

Tabel 4. Parameter Tie Back Anchor

\begin{tabular}{lccc}
\hline \multicolumn{1}{c}{ Parameter } & Nama & Nilai & Satuan \\
\hline Jenis Perilaku & Jenis material & Elastis & - \\
\hline Kekakuan normal & EA & $2.10^{5}$ & $\mathrm{kN}$ \\
\hline Spasi keluar bidang gambar & $\mathrm{L}_{\mathrm{S}}$ & 3 & $\mathrm{~m}$ \\
\hline Gaya maksimum & $F_{\text {maks }}$ & $1.10^{15}$ & $\mathrm{kN}$ \\
\hline Gaya prategang & $P$ & 121,68 & $\mathrm{kN} / \mathrm{m}$ \\
\hline
\end{tabular}

Tabel 5. Parameter Tie Grout Body (Bonded)

\begin{tabular}{cccc}
\hline Parameter & Nama & Nilai & Satuan \\
\hline Kekakuan normal & EA & $1,5.10^{5}$ & $\mathrm{kN}$ \\
\hline
\end{tabular}

\section{Analisis galian dengan dinding penahan tanah (DPT)}

Simulasi pada kondisi ini hanya menggunakan dinding penahan tanah, kemudian dilihat kondisi ini masih aman atau tidak berdasarkan angka keamanan dan deformasi dindingnya. Analisis ini dilakukan pada kondisi galian tanah drained atau jangka panjang. Berikut hasil output dari program hingga galian kedalaman 9 meter, berupa nilai deformasi dinding dan angka keamanan pada Gambar 6. Dilihat dari besaran deformasi dan angka keamanan, galian terbilang tidak aman.

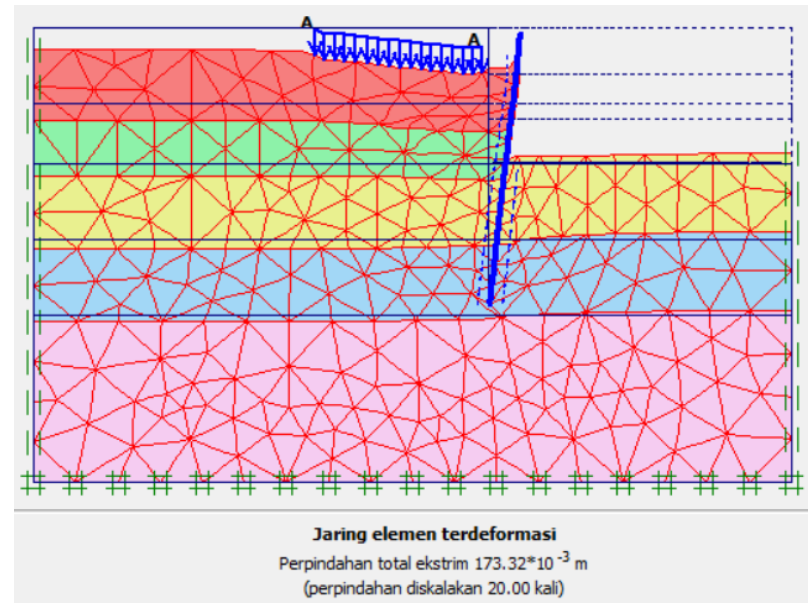

Gambar 6. Galian hingga kedalaman 9 meter menggunakan DPT

\section{Analisis galian menggunakan DPT dengan tie back anchor}

Hasil analisis tanpa menggunakan tie back anchor ternyata tidak memenuhi syarat aman yang telah ditentukan, maka dari itu dilakukan analisis dengan bantuan tie back anchor sebagai penunjang. Analisis ini perlu dilakukan dengan dua kondisi. Analisis yang pertama adalah analisis dengan kondisi undrained dan yang kedua adalah analisis dengan kondisi drained.

Berdasarkan persyaratan angka keamanan (SF>1.5), hasil dari seluruh analisis dengan bantuan tie back anchor sebagai penunjang memiliki angka keamanan memenuhi persyaratan minimal. Namun, untuk mencegah dan menghindari hal yang tidak diinginkan pada jenis tanah tertenu, maka syarat angka keamanan perlu dinaikkan di 
atas syarat angka normal. Karena alasan di atas, maka dalam analisis ini digunakan angka keamanan $\mathrm{SF}>2$. Rekapitulasi analisis dengan bantuan tie back anchor dapat dilihat pada Tabel 6. dan Grafik 1.

Tabel 6. Rekapitulasi Angka Keamanan dan Deformasi pada Galian Undrained dan Drained dengan Tie Back Anchor dan Dinding Penahan Tanah

\begin{tabular}{cccccc}
\hline \multirow{2}{*}{ Tahapan ke- } & \multirow{2}{*}{$\begin{array}{c}\text { Urutan } \\
\text { Pekerjaan }\end{array}$} & \multicolumn{2}{c}{ Undrained } & \multicolumn{2}{c}{ Drained } \\
\cline { 2 - 6 } & Penggalian 3 m & 4.8693 & 1.439 & 2.7389 & 1.853 \\
\hline 1 & Pemasangan tie back anchor 1 & 4.8723 & 1.134 & 2.9377 & 1.77 \\
\hline 2 & Penggalian 6 m & 4.3880 & 1.929 & 2.3490 & 2.658 \\
\hline 3 & Pemasangan tie back anchor 2 & 4.7087 & 1.927 & 2.6349 & 2.661 \\
\hline 4 & Penggalian $9 \mathrm{~m}$ & 3.5499 & 1.912 & 2.3394 & 3.292 \\
\hline 5 & & & &
\end{tabular}

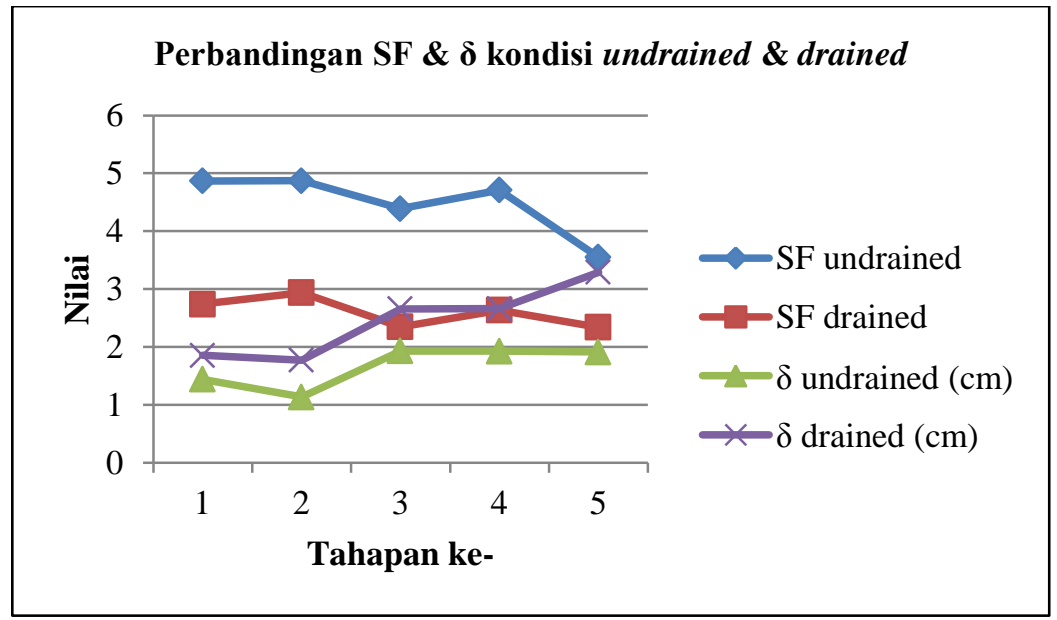

Grafik 1. Perbandingan safety factor \& deformasi dinding kondisi undrained dan drained

\section{KESIMPULAN DAN SARAN}

\section{Kesimpulan}

Berdasarkan analisis yang dilakukan, didapatkan beberapa kesimpulan sebagai berikut:

1. Analisis pada program menunjukkan bahwa kondisi drained memiliki angka keamanan 2.3394 pada akhir penggalian dan besar deformasi sebesar $3.292 \mathrm{~cm}$.

2. Analisis pada program menunjukkan bahwa kondisi undrained memiliki angka keamanan 3.5499 pada akhir penggalian dan besar deformasi sebesar $1.912 \mathrm{~cm}$.

3. Analisis pada program menunjukkan bahwa kondisi drained memiliki angka keamanan lebih kecil dari kondisi undrained. Hal ini membenarkan teori bahwa pada kondisi drained, tanah memiliki permeabilitas tinggi sehingga air dapat dengan mudah mengalir keluar masuk pada tanah.

\section{Saran}

Berdasarkan kesimpulan yang telah dibuat, maka saran yang dapat diberikan yaitu:

1. Pekerjaan dewatering dalam pembangunan basement dapat berdampak pada lingkungan sekitar, sehingga perlu peninjauan dan wawasan yang luas terhadap karakteristik tanah sekitar untuk meminimalisir dampak yang mungkin akan timbul. 
2. Pekerjaan galian dan basement pada tanah dispersif sebaiknya dihindari, atau tetap dilakukan dengan penangan khusus seperti, menaikkan syarat angka keamanan pada proses perhitungan untuk mencegah kemungkinan terburuk yang akan terjadi.

3. Pada tanah dispersif perlu keberhati-hatian dalam mendesain dan kesalahan sekecil apapun pada desain tidak dapat ditoleransi karena tanah dispersif dapat mempengaruhi kriteria desain dan berujung pada kegagalan kostruksi.

4. Galian pada jenis tanah sensitif seperti dispersif, perlu adanya dinding penahan tanah yang kuat dan impermeabel agar dapat mencegah keruntuhan tanah dan dinding penahan tanah.

\section{DAFTAR PUSTAKA}

Asiyanto (2008). Metode Konstruksi Bangunan Pelabuhan. Penerbit Universitas Indonesia, Jakarta.

Das, Braja M., Principles of Foundation Engineering 4th Edition,1998, PWS Publishing, Pacific Grove.

Day, Robert W. (2005). Foundation Engineering Hand Book. McGraw-Hill Education, United States.

Joint Departments of the Army, the Air Force, and the Navy, USA, Technical Manual TM 5-818- 5/AFM 88-5, Chap 6/NAVFAC P418, Dewatering and Groundwater Control. 